\title{
DUAL BOUNDARY ELEMENT ANALYSIS FOR FATIGUE BEHAVIOR OF MISSILE STRUCTURES
}

\author{
Shiang-Woei Chyuan ${ }^{1}$, Jiann-Hwa Lin ${ }^{2}$, Jeng-Tzong Chen ${ }^{2 *}$ and Dauh-Churn Liu ${ }^{1}$ \\ ${ }^{1}$ Chung-shan Institute of Science and Technology \\ Lung-tan, Taiwan 325, R.O.C. \\ ${ }^{2}$ Department of Harbor and River Engineering \\ Taiwan Ocean University \\ Keelung, Taiwan 202, R.O.C.
}

Key Words: boundary elements, damage tolerance, fatigue crack growth, fracture mechanics, stress intensity factors.

\begin{abstract}
The fatigue behavior of a crack in a missile structure is studied using the dual boundary integral equations developed by Hong and Chen (1988). This method, which incorporates two independent boundary integral equations, uses the displacement equation to model one of the crack boundaries and the traction equation to the other. A single domain approach can be performed efficiently. The stress intensity factors are calculated and the paths of crack growth are predicted. In order to evaluate the results of dual BEM, four examples with FEM results are provided. Two practical examples, cracks in a V-band and a solid propellant motor are studied and are compared with experimental data. Good agreement is found.
\end{abstract}

\section{INTRODUCTION}

In mechanical design, a V-band is one of the best joints to connect two components, but it usually faces crack problems in some critical areas. Also, a crack in the solid rocket motor sometimes results in a catastrophic failure (Chen and Leu, 1998). In studying crack problems using numerical techniques, the analyst may encounter problems with singularities. Singular behavior is often ignored with the expectation that the error will be limited to the vicinity of the singularity. However, it is very important to show how strong the singular behavior is, e.g., the stress intensity factor of fracture mechanics. In particular, this factor is very important to predict the crack growth in the damage tolerance design. In finite elements, special singular or hybrid elements are sometimes used instead of the quarter-point rule; e.g., MSC/NASTRAN Version 68 (Chen et al., 1996) provides the capabilities of singular CRAC2D and CRAC3D elements for crack problems of two and three-dimensional problems, respectively.

For problems with a degenerate boundary, e.g., crack problems (Chen, 1988; Portela et al., 1992, 1993; Mi and Aliabadi, 1992; Fedelinski and Aliabadi, 1994; Leitao et al., 1995; Salgado and Aliabadi, 1998), flow around sheet piles (Chen and Hong, 1993; Chen et al., 1994), an incomplete partition in a room (Chen and Chen, 1998; Chen and Wong, 1998) and a thin airfoil in aerodynamics (Wang et al., 1990; Chen and Hong, 1992), singularity exists, and the dual integral formulation has been applied successfully for the BEM approach. Using the dual integral formulation, all the well-posed boundary value problems can be solved even though a degenerate

*Correspondence addressee 
boundary is present. It is well known that the DBEM (dual boundary element method) is particularly suitable for the problem of extreme localization and concentration with singularity. The DBEM solution is based on the complete formulation of the dual integral equations. The long standing abstruseness of the nonuniqueness problem in BEM has been solved, and the general purpose programs have been implemented by Chen and his coworkers (Chen and Hong, 1992, 1999). For the problems of crack growth, remesh near the tip using FEM is unavoidable, while additional boundary elements are only needed in the dual BEM as shown in Fig. 1. Therefore, the dual BEM approach has been widely used, e.g., cracks in welded structures (Lie and Lan, 1998) and rock samples (Kayupov et al., 1999).

In this paper, the dual BEM is extended to solve crack problems in missile structures. Two cases are studied: one is a V-band component, and the other is propellant in a solid rocket motor. The concept of damage tolerance is considered (Bannantine, 1990). In order to verify the validity of the dual BEM, two test examples are worked out and the results are compared with analytical and FEM solutions. The stress intensity factors are determined and the paths of crack growth for the components in the missile system are predicted. Also, numerical results are compared with experimental data for the crack path in solid propellant grain.

\section{REVIEW OF DUAL BOUNDARY INTEGRAL EQUATIONS FOR DOMAIN POINTS OF CRACK PROBLEMS}

In this section, we review the dual boundary integral equations of the domain points for crack problems.

\section{Betti's Law}

Let $\left(b_{i}, u_{i}, t_{i}\right)$ and $\left(b_{i}^{*}, t_{i}^{*}, u_{i}^{*}\right)$ be two equilibrium states in a linearly elastic body where $b_{i}$ and $b_{i}^{*}$ are the body forces; $t_{i}$ and $t_{i}^{*}$ denote the boundary tractions; and $u_{i}$ and $u_{i}^{*}$ are the displacements. Betti's law gives

$$
\int_{D}\left(u_{i} b_{i}^{*}-u_{i}^{*} b_{i}\right) d V=-\int_{B}\left(u_{i} t_{i}^{*}-u_{i}^{*} t_{i}\right) d B
$$

where $D$ is a domain with boundary $B$. It can be recast into the theory of self-adjoint operator $\mathcal{L}$ simply as

$$
\langle\mathcal{L} u \mid v\rangle=\langle u \mid \mathcal{L} v\rangle
$$

where
Stage 1: crack length $a=a_{0}$
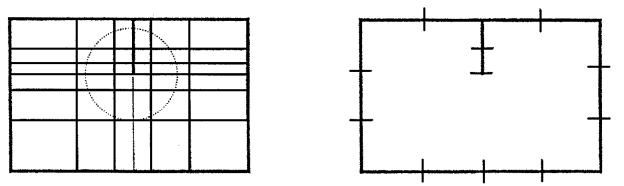

Stage 2: crack length $a=a_{0}+\Delta a$

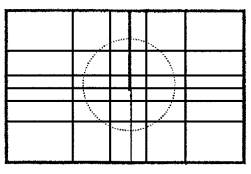

Remesh in FEM

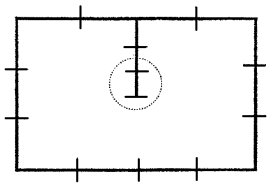

Additional mesh in BEM
Fig. 1 FEM and BEM meshes for crack growth

$$
\mathcal{L}=\left[\begin{array}{cc}
\mathcal{D} & 0 \\
0 & -\mathcal{B}
\end{array}\right] .
$$

If the material is elastic and isotropic, the operator $\mathcal{D}$ can be expressed explicitly as

$$
D_{i j}=(\lambda+G) \partial_{i} \partial_{j}+G \delta_{i j} \partial_{k} \partial_{k}
$$

while $\mathcal{B}$ is the traction operator defined by

$$
B_{i j}=\lambda n_{i} \partial_{j}+G\left(n_{j} \partial_{i}+\delta_{i j} n_{k} \partial_{k}\right)
$$

where $\lambda$ and $G$ are Lame's constants; $n_{i}$ is the direction cosine of the unit outward normal to the boundary; $\delta_{i j}$ denotes Kronecker delta symbol; and $\partial_{i}$ is the partial differential operator. Note that the equations of equilibrium for the two states, $u_{j}$ and $u_{j}^{*}$, are

$$
\begin{aligned}
& D_{i j} u_{j}(x)+b_{i}(x)=0, x \text { in } D, \\
& D_{i j} u_{j}^{*}(x)+b_{i}^{*}(x)=0, x \text { in } D,
\end{aligned}
$$

with the Cauchy formula

$$
\begin{aligned}
& B_{i j} u_{j}(x)=t_{i}(x), x \text { on } B, \\
& B_{i j} u_{j}^{*}(x)=t_{i}^{*}(x), x \text { on } B,
\end{aligned}
$$

By choosing

$$
u_{j}^{*}=v_{j}
$$

we can obtain

$$
\int_{D}\left(v_{i} D_{i j} u_{j}-u_{i} D_{i j} v_{j}\right) d V=\int_{B}\left(v_{i} B_{i j} u_{j}-u_{i} B_{i j} V_{j}\right) d B
$$

Now we choose specifically: 


$$
\begin{aligned}
& t_{i}^{*}(x)=B_{i k} v_{k}(x)=B_{i k}(x) U_{k j}(x, s) e_{j}^{*}(s)=T_{i j}(x, s) e_{j}^{*}(s), \\
& \begin{aligned}
b_{i}^{*}(x) & =-D_{i k}(x) v_{k}(x)=-D_{i k}(x) U_{k j}(x, s) e_{j}^{*}(s) \\
& =\delta_{i j}(\mathrm{x}, \mathrm{s}) e_{j}^{*}(s)
\end{aligned} \\
& u_{i}^{*}(x)=v_{i}(x)=U_{i j}(x, s) e_{j}^{*}(\mathrm{~s}),
\end{aligned}
$$

where $U_{i j}(x, s)$ and $T_{i j}(x, s)$ are the Kelvin free-space Green's functions (or fundamental solutions) of the $i$-direction responses for displacement and traction at the point $x$, respectively, due to a concentrated load in the $j$-direction at the point $s$; and $e_{j}^{*}(\mathrm{~s})$ is an arbitrary unit-concentrated load at the point $s$. Then we have Somigliana's identity (Banerjee and Butterfield, 1981):

$$
\int_{B}\left[U_{i j}(x, s) t_{i}(x)-T_{i j}(x, s) u_{i}(x)\right] d B(x)= \begin{cases}u_{j}(s), & s \in D \\ 0, & s \notin D\end{cases}
$$

By changing $x$ and $s$, Eq. 15 is changed to

$$
\int_{B}\left[U_{k i}(s, x) t_{k}(s)-T_{k i}(s, x) u_{k}(s)\right] d B(s)= \begin{cases}u_{i}(x), & x \in D \\ 0, & x \notin D\end{cases}
$$

In deriving Eq. (15), we have omitted the unit vector $e_{j}^{*}$ from both sides of the equation because of its arbitrariness. In order to have an additional and independent equation for the problem with a degenerate boundary, we apply the traction operator $B_{p i}$ to Eq. 16 and define

$$
\begin{aligned}
& B_{p i}(x)\left\{U_{k i}(s, x)\right\}=L_{k p}(s, x), \\
& B_{p i}(x)\left\{T_{k i}(s, x)\right\}=M_{k p}(s, x) .
\end{aligned}
$$

It then follows that

$\int_{B}\left[L_{k p}(x, s) t_{k}(s)-M_{k p}(s, x) u_{k}(s)\right] d B(s)= \begin{cases}t_{p}(x), & x \in D \\ 0, & x \notin D\end{cases}$

Eqs. (16) and (19) are termed the dual boundary integral equations for the point $x$ in the domain. It is noted that this definition is different from that defined by Buecker (Buecker, 1973). A detailed discussion for the dual boundary integral equations can be found in the review article of Chen and Hong (1999).

\section{DERIVATIONS OF DUAL BOUNDARY INTEGRAL EQUATIONS FOR THE BOUNDARY POINTS}

Equations (16) and (19) are derived for a point in the interior domain. By moving the point to the boundary, we are immediately confronted with the problem of singularities and improper integrals. Eq. (16) reduces to

$$
\begin{aligned}
& \int_{B} U_{k i}(s, x) t_{k}(s) d B(s)+\beta_{i j} u_{j}(x) \\
& -C P V \int_{B} T_{k i}(s, x) u_{k}(s) d B(s)=\delta_{i j} u_{j}(x)
\end{aligned}
$$

where $\beta_{i j}$ depends on the solid angle and $C P V$ denotes the Cauchy principal value. Similarly, Eq. 16 becomes

$$
\begin{aligned}
& \int_{B} U_{k i}(s, x) t_{k}(s) d B(s)+\left(-\delta_{i j}+\beta_{i j}\right) u_{j}(x) \\
& -C P V \int_{B} T_{k i}(s, x) u_{k}(s) d B(s)=0
\end{aligned}
$$

where $\beta_{i j}$ reduces to $1 / 2 \delta_{i j}$ when $x$ is on the smooth boundary (Hartmann, 1981, 1982). Eq. (20) reduces to

$$
\begin{aligned}
\frac{1}{2} u_{i}(x) & =\int_{B} U_{k i}(s, x) t_{k}(s) d B(s)-C P V \int_{B} T_{k i}(s, x) u_{k}(s) d B(s), \\
x & \text { on } B
\end{aligned}
$$

Now applying the traction operator to Eq. 22, and noting that

$$
\begin{aligned}
& B_{p i}(x)\left\{\int_{B} U_{k i}(s, x) t_{k}(s) d B(s)\right\} \\
& =B_{p i}(x) \int_{B-B_{\varepsilon}} U_{k i}(s, x) t_{k}(s) d B(s) \\
& =C P V \int_{B} L_{k p}(s, x) t_{k}(s) d B(s)
\end{aligned}
$$

where the first equality results from the integral over the small detour around $x \in B_{\varepsilon}$, and $B_{\varepsilon}$ denotes a small spherical or circular detour of vanishing radius $\varepsilon$ and center at $x$. The second equality stems from the boundary terms due to the traction operator using Leibnitz' rule canceling themselves out, and defining that

$$
\begin{aligned}
& B_{p i}(x)\left\{C P V \int_{B} T_{k i}(s, x) u_{k}(s) d B(s)\right\} \\
& \equiv H P V \int_{B} M_{k p}(s, x) u_{k}(s) d B(s),
\end{aligned}
$$


we have

$$
\begin{aligned}
\frac{1}{2} t_{p}(x)= & C P V \int_{B} L_{k p}(s, x) t_{k}(s) d B(s) \\
& -H P V \int_{B} M_{k p}(s, x) u_{k}(s) d B(s), x \text { on } B
\end{aligned}
$$

where $H P V$ denotes the Hadamard principal value (Hadamard, 1952). Eqs. (22) and (25) are termed the dual boundary integral equations for a boundary point.

\section{DUAL BOUNDARY ELEMENT FORMULATION FOR CRACK PROBLEMS}

By discretizing the boundary $B$ into constant elements in Eqs. (22) and (25), we have

$$
\begin{aligned}
\frac{1}{2} u_{i}(x)= & \sum_{l=1}^{N} t_{k}\left(s_{l}\right) \int_{B_{l}} U_{k i}(s, x) d B(s) \\
& -\sum_{l=1}^{N} u_{k}\left(s_{l}\right) C P V \int_{B_{l}} T_{k i}(s, x) d B(s) \\
\frac{1}{2} t_{i}(x)= & \sum_{l=1}^{N} t_{k}\left(s_{l}\right) C P V \int_{B_{l}} L_{k i}(s, x) d B(s) \\
& -\sum_{l=1}^{N} u_{k}\left(s_{l}\right) H P V \int_{B_{l}} M_{k i}(s, x) d B(s)
\end{aligned}
$$

where $N$ is the number of boundary elements and $B_{l}$ is the $l$ th boundary element. For a two-dimensional problem, Eqs. (26) and (27) can be written in matrix forms as shown below

$$
\begin{aligned}
& {[C]_{2 N \times 2 N}\{u\}_{2 N \times 1}} \\
& =[U]_{2 N \times 2 N}\{t\}_{2 N \times 1}-[T]_{2 N \times 2 N}\{u\}_{2 N \times 1} \\
& {[C]_{2 N \times 2 N}\{t\}_{2 N \times 1}} \\
& =[L]_{2 N \times 2 N}\{t\}_{2 N \times 1}-[M]_{2 N \times 2 N}\{u\}_{2 N \times 1}
\end{aligned}
$$

where $\{u\}$ and $\{t\}$ are the column vectors of boundary displacement and traction, and $[C]$ is a matrix of free terms. Eqs. (28) and (29) can be reduced to

$$
\begin{aligned}
& {[\bar{T}]\{u\}=[U]\{t\}} \\
& {[M]\{u\}=[\bar{L}]\{t\}}
\end{aligned}
$$

where $[\bar{T}]$ and $[\bar{L}]$ differ from $[T]$ and $[L]$ by a matrix of free terms. It is found that Eq. (28) is not sufficient to provide enough constraint equations for crack problems; thus, Eq. (29) is needed. Combining Eqs. (28) and (29), the double unknowns on the degenerate boundary can be determined easily.

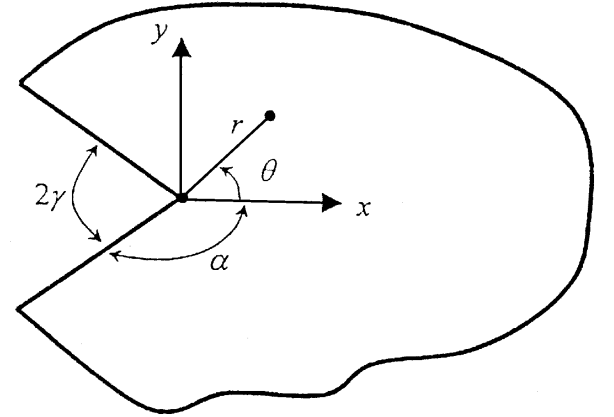

Fig. 2 Sharp-notch geometry in polar and cartesian coordinate systems

\section{DETERMINATION OF STRESS INTENSITY FACTOR AND PREDICTION OF FATIGUE CRACK GROWTH}

The V-band joint between two diverse components has been found to fail during sevice life. Also, cracks in solid propellant grain propagate under thermal loading. In damage tolerance design, an initial crack is assumed. The damage tolerance concept is based on linear elastic fracture mechanics, for all cases in which the inherent inelastic deformation around the crack tip is small.

Two basic crack deformations are considered: the opening mode (mode I), and the sliding mode (mode II). For cases 1 and 2, only mode $\mathrm{I}$ is considered. For the crack in a V-band structure, modes I and II are both discussed.

At the tip of a sharp notch, the stress intensity factors are the coefficients of the stess singularities and may be defined in a manner similar to that used by Irwin (Irwin, 1957) for cracks, as follows

$$
K_{I}=\sqrt{2 \pi} \lim _{\rightarrow} r^{1-\lambda} \sigma_{y y}(r, \theta=0, \alpha)
$$

and

$$
K_{I I}=\sqrt{2 \pi} \lim _{\rightarrow} r^{1-\zeta_{1}} \sigma_{x y}(r, \theta=0, \alpha)
$$

that is

$$
\begin{aligned}
& K_{I}=\sqrt{2 \pi} \lambda_{1} \beta_{1}\left(1+\lambda_{1}-\lambda_{1} \cos 2 \alpha-\cos 2 \lambda_{1} \alpha\right) \\
& K_{I I}=\sqrt{2 \pi} \zeta_{1} \delta_{1}\left(-1+\zeta_{1}-\zeta_{1} \cos 2 \alpha+\cos 2 \zeta_{1} \alpha\right)
\end{aligned}
$$

where $\sigma_{y y}$ and $\sigma_{x y}$ are the stress fields in the neighbourhood of the tip, $\alpha$ is the angle as shown in Fig. 2 , and $\lambda_{1}, \beta_{1}$ and $\zeta_{1}, \delta_{1}$ are the dominant eigenpairs of the opening and sliding modes, respectively.

As the crack behavior is completely determined by the stress intensity factors, Eqs. (32) to (35), for 
the case $\alpha=180^{\circ}$ the crack-tip stresses are given by

$$
\begin{aligned}
\sigma_{x x}= & \frac{K_{I}}{\sqrt{2 \pi r}} \cos \frac{\theta}{2}\left(1-\sin \frac{\theta}{2} \sin \frac{3 \theta}{2}\right) \\
& +\frac{K_{I I}}{\sqrt{2 \pi r}} \sin \frac{\theta}{2}\left(2+\cos \frac{\theta}{2} \cos \frac{3 \theta}{2}\right) \\
\sigma_{y y}= & \frac{K_{I}}{\sqrt{2 \pi r}} \cos \frac{\theta}{2}\left(1+\sin \frac{\theta}{2} \sin \frac{3 \theta}{2}\right) \\
& -\frac{K_{I I}}{\sqrt{2 \pi r}} \sin \frac{\theta}{2} \cos \frac{\theta}{2} \cos \frac{3 \theta}{2}
\end{aligned}
$$

and

$\sigma_{x y}=\frac{K_{I}}{\sqrt{2 \pi r}} \cos \frac{\theta}{2} \sin \frac{\theta}{2} \cos \frac{3 \theta}{2}+\frac{K_{I I}}{\sqrt{2 \pi r}} \cos \frac{\theta}{2}\left(1-\sin \frac{\theta}{2} \sin \frac{3 \theta}{2}\right)$

The criterion commonly used for the path of crack growth is the maximum principal stress criterion (Erdogan and Sih, 1972) which postulates that fracture will occur in a direction perpendicular to that of maximum principal stress at the crack tip. The cracktip circumferential stresses, derived from Eqs. (36) to (38), can be expressed as

$$
\sigma_{\theta \theta}=\frac{1}{\sqrt{2 \pi r}} \cos \frac{\theta}{2}\left[K_{I} \cos ^{2} \frac{\theta}{2}-\frac{3}{2} K_{I I} \sin \theta\right]
$$

and

$$
\sigma_{r \theta}=\frac{1}{2 \sqrt{2 \pi r}} \cos \frac{\theta}{2}\left[K_{I} \sin \theta+K_{I I}(3 \cos \theta-1)\right]
$$

If the stress $\sigma_{r \theta}$ is equal to zero, then $\sigma_{\theta \theta}$ will be principal stress. The corresponding principal direction, $\theta=\theta_{t}$, can be evaluated from the condition $\sigma_{r \theta}=0$ which leads to

$$
K_{I} \sin \theta_{t}+K_{I I}\left(3 \cos \theta_{t}-1\right)=0
$$

By means of simple trigonometric relationships, this equation can be transformed into a quadratic form whose roots, given by

$$
\tan \frac{\theta_{t}}{2}=\frac{1}{4}\left[\frac{K_{I}}{K_{I I}} \pm \sqrt{\left(\frac{K_{I}}{K_{I I}}\right)^{2}+8}\right]
$$

provide an easy way to evaluate $\theta_{t}$.

Based on the fundamental postulate of linear elastic fracture mechanics, the stress intensity factor criterion for fracture can be stated as

$$
K_{I_{e q}}=K_{I_{c}}
$$

where $K_{I_{e q}}$ represents an equivalent mode I stress intensity factor, defined in a mixed-mode analysis and $K_{I_{c}}$ represents the plane strain fracture toughness which is a critical value of the stress intensity factor, taken as a property of the material.

For simplicity, we considered the loading cycle has a constant amplitude and is described by a static load level with a stress amplitude ratio $R$ defined as

$$
R=\frac{\sigma_{\min }}{\sigma_{\max }}=\frac{K_{I_{e q \min }}}{K_{I_{e q \max }}}
$$

where $\sigma_{\min }$ and $\sigma_{\max }$ denote the minimum and maximum applied stress, and $K_{I_{\text {eq } \max }}$ and $K_{I_{\text {eq } \min }}$ are the corresponding stress intensity factors. Hence, when the analysis is performed at the maximum stress level, the stress intensity factor range, $\Delta K_{I_{e q}}$, is given by

$$
\Delta K_{I_{e q}}=K_{I_{e q \max }}-K_{I_{e q \text { min }}}=K_{I_{\text {eq } \max }}(1-R)
$$

The crack growth rate, $\frac{d a}{d N}$, can be computed by the Paris law (Paris, 1962), given by

$$
\frac{d a}{d N}=C\left(\Delta K_{I_{e q}}\right)^{m}
$$

where $C$ and $m$ are the empirical constants for the material.

In Fig. 1, the crack length is $a_{0}$ in stage 1 , and the crack propagates with a length $\Delta a$ in stage 2 . Remeshing near the crack tip is needed for FEM. However, only one additional boundary element should be constructed using the dual BEM. In engineering practice, we can save much time in data preparation. In the following examples, the dual BEM will be employed to solve for crack problems. Also, the path of crack growth is discussed.

\section{RESULTS AND DISCUSSIONS FOR NUMERICAL SOLUTIONS USING THE DUAL BEM}

\section{Test examples}

In order to verify the accuracy of the present formulation of the dual BEM, case 1, a single-edge crack problem, and case 2 , a double-edge crack problem, subjected to uniform tension are considered as shown in Fig. 3 and Fig. 4.

Case 1:

As shown in Fig. 3, the parameters are considered as below: elastic modulus $E=200000 \mathrm{kgf} / \mathrm{mm}^{2}$, Poisson's ratio $v=0.25$, loading $\sigma=10 \mathrm{kgf} / \mathrm{mm}^{2}$, the constants of Paris law $C=4.624 \times 10^{-12}, m=3.3$, the stress ratio $R=2 / 3$ and crack length $a=0.1 \mathrm{~mm}$. 


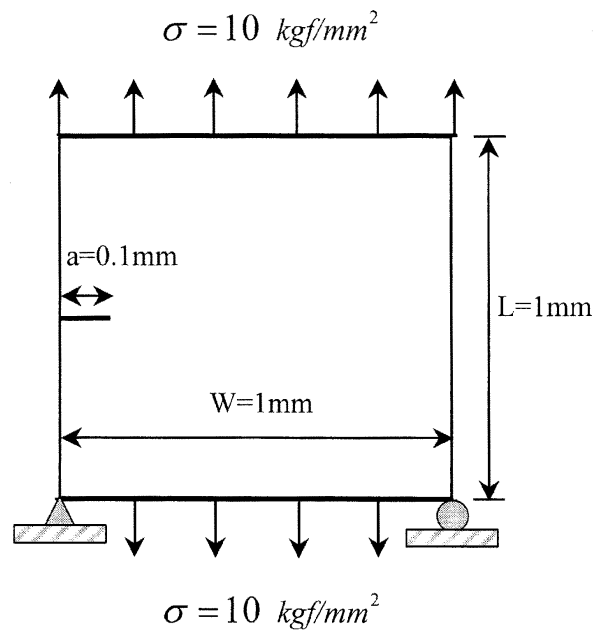

Fig. 3 Case 1: Single-edge crack problem

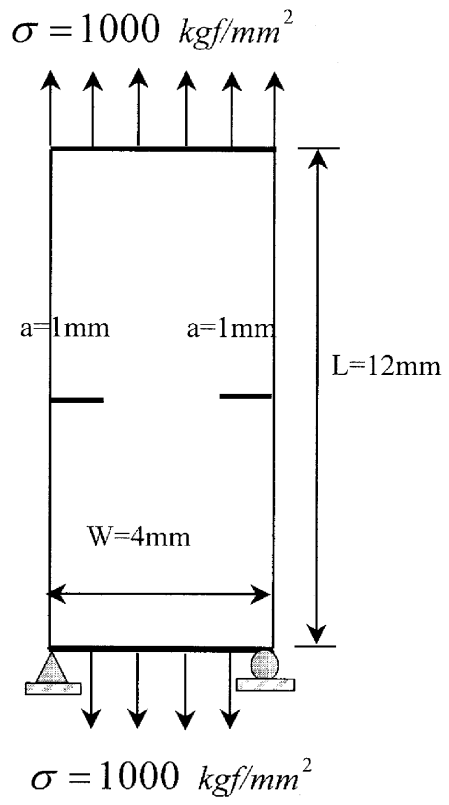

Fig. 4 Case 2: Double-edges crack problem

\section{Case 2:}

As shown in Fig. 4, the parameters are considered as below: elastic modulus $E=1000 \mathrm{kgf} / \mathrm{mm}^{2}$, Poisson's ratio $v=0.3$, loading $\sigma=1000 \mathrm{kgf} / \mathrm{mm}^{2}$, the constants of Paris law $C=4.624 \times 10^{-12}, m=3.3$, the stress ratio $R=2 / 3$ and crack length $a=1.0 \mathrm{~mm}$.

The stress intensity factor is obtained and the crack path is predicted by using the dual BEM program. In the FEM implementation, the MSC/ NASTRAN program (Chen et al., 1996) was also utilized to obtain the stress intensity factor. Both the CRAC2D and CRAC3D elements in NASTRAN were implemented for the double-edge crack problems. Figs. 5, 6, 7, 8, 9 and 10, show the element mesh and the path of crack growth we predicted for the two

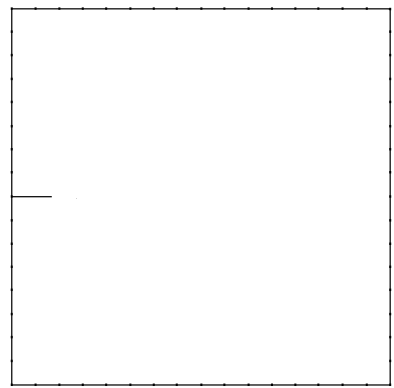

Fig. 5 Boundary element mesh in case 1

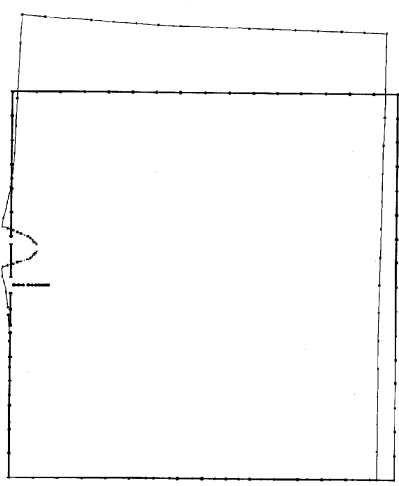

Fig. 6 Deformed plot for case 1

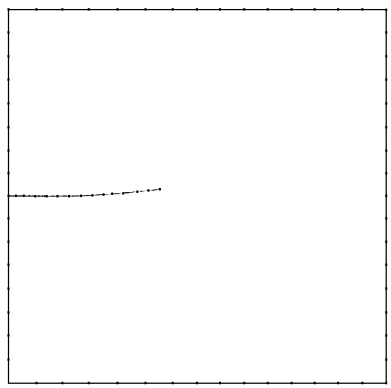

Fig. 7 Path of the crack growth in case 1

cases. The analytical solutions for the two cases are shown below (Broek, 1988):

Case 1: Single-edge crack problem

$$
\begin{aligned}
K_{I}= & \sigma \sqrt{\pi a}\left[1.12-0.213\left(\frac{a}{W}\right)+10.56\left(\frac{a}{W}\right)^{2}-21.74\left(\frac{a}{W}\right)^{3}\right. \\
& \left.+30.42\left(\frac{a}{W}\right)^{4}\right]
\end{aligned}
$$

Case 2: Double-edges crack problem

$$
K_{I}=\sigma \sqrt{\pi a}\left[1.99+0.76\left(\frac{a}{W}\right)-8.48\left(\frac{a}{W}\right)^{2}+2.736\left(\frac{a}{W}\right)^{3}\right]
$$

where $a$ is the crack length and $W$ is the width of the 
(a)

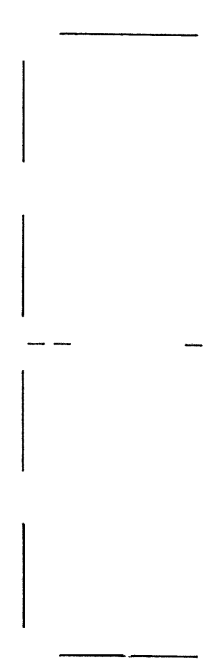

(b)

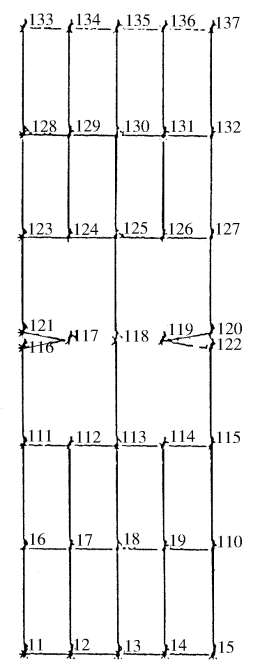

(c)

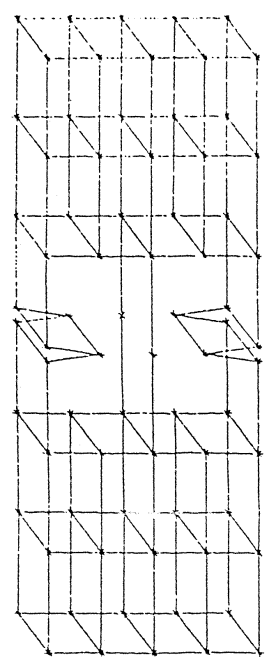

Fig. 8 (a) Boundary element mesh in case 2. (b) Finite element mesh using CRAC2D elements in NASTRAN. (c) Finite element mesh using CRAC3D elements in NASTRAN

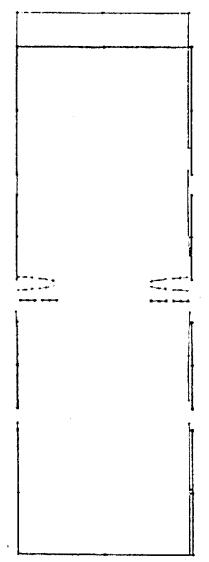

Fig. 9 Deformed plot for case 2

plate. Table 1 shows the stress intensity factors calculated by the dual BEM, FEM and the analytical solution for case 1. As shown in Table 2, we use the same number of elements in case 2 for FEM (2D or $3 \mathrm{D}$ simulation) and the dual BEM, and the results indicate that the accuracy using the dual BEM is better than those of using FEM. These two examples are demonstrated to show the validity of the dual BEM since the agreement between the FEM and the dual BEM is good.

\section{Case 3 V-band joint structure}

Figure 11 shows the V-band structure which connects two diverse components in missile structure. In the V-band component, the parameters are considered as below: elastic modulus $E=19950 \mathrm{kgf} / \mathrm{mm}^{2}$, Poisson's ratio $v=0.27$, initial crack length $a=0.125$

Table 1 Stress intensity factors for case 1

\begin{tabular}{cccc}
\hline & FEM & DBEM & exact sol. \\
\hline$K_{I}$ & 6.255 & 6.817 & 6.635 \\
Errors $(\%)$ & 5.727 & 2.743 & \\
\hline
\end{tabular}

Table 2 Stress intensity factors for case 2

FEM-3D FEM-2D DBEM exact

sol.

\begin{tabular}{ccccc}
\hline No. of elements & 18 & 18 & 18 & \\
No. of nodes & 137 & 37 & 36 & \\
$K_{I}$ & 2138 & 2021 & 2066 & 2077.5 \\
Errors (\%) & 2.9 & 2.7 & 0.482 & \\
\hline
\end{tabular}

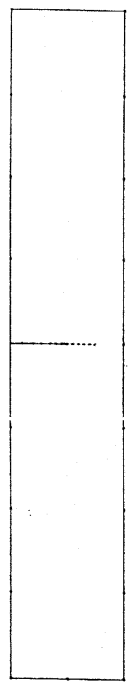

Fig. 10 Path of crack growth in case 2

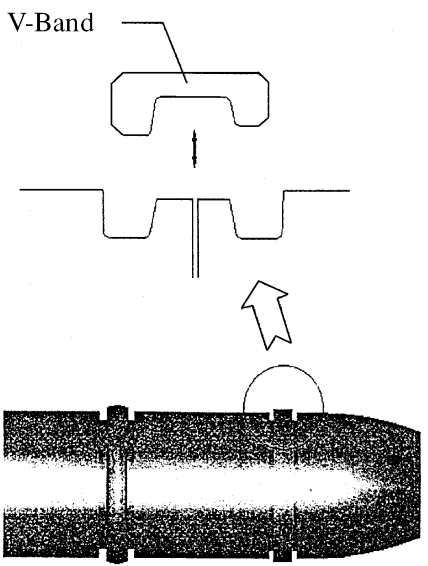

Fig. 11 Definition sketch for a V-band structure

$\mathrm{mm}$, loading $\sigma=4.84 \mathrm{kgf} / \mathrm{mm}^{2}$, the constants of Paris law $C=4.624 \times 10^{-12}$ and $m=3.3$, stress ratio $R=2 / 3$. 
(a)

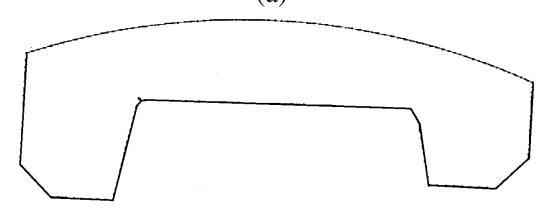

(b)

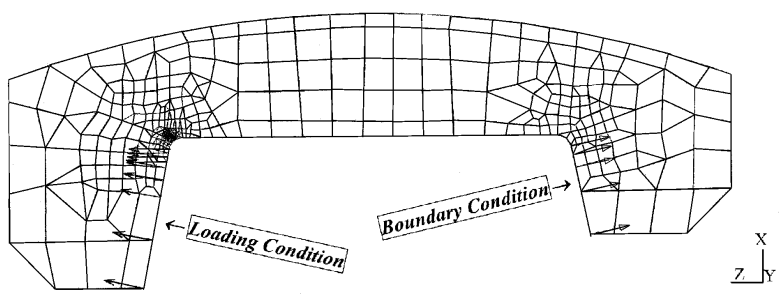

Fig. 12 (a) Boundary element mesh. (b) Finite element mesh

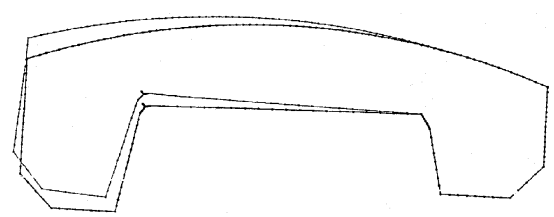

Fig. 13 Deformed plot for the V-band structure

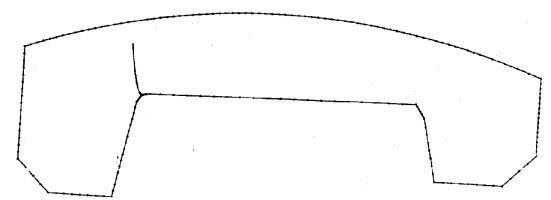

Fig. 14 Path of crack growth under fatigue loading in case 3

Figs. 12(a) and (b) show the meshes of BEM and FEM, respectively. Fig. 13 is the deformed plot for the V-band structure subjected to loading. Also, we can predict the path of crack growth in the V-band joint structure which is shown in Fig. 14. The stress intensity factor by using the dual BEM and FEM are shown in Table 3. Although a little difference is found between FEM (Chyuan and Liu, 1996) and DBEM, it is acceptable in general engineering practice.

\section{Case 4 Solid propellant motor with a stress reliever}

Figure 15 shows a solid rocket motor with a stress reliever. In the previous paper (Chen and Leu, 1998), a stress analysis for the solid rocket motor has been done. The possible failure position was also found at the area of maximum stress. An initial crack is assumed there. In this case, the parameters are considered as below: elastic modulus $E=30000 \mathrm{kgf} / \mathrm{mm}^{2}$, Poisson's ratio $v=0.499$, initial crack length $a=1.0$ $\mathrm{mm}$, the constants of Paris law (Williams, 1984) $C=6$. $68 \times 10^{-12}$ and $m=2.75$, stress ratio $R=2 / 3$. A thermal loading is applied. The change in temperature is $75^{\circ} \mathrm{C}$
Table 3 Stress intensity factors for case 3

\begin{tabular}{ccc}
\hline & FEM & DBEM \\
\hline$K_{I}$ & 36.119 & 34.874 \\
$K_{I I}$ & 8.748 & 6.561 \\
\hline
\end{tabular}

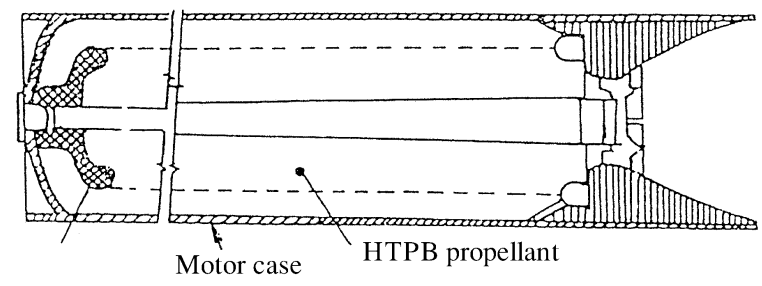

Fig. 15 The solid rocket motor with a stress reliever

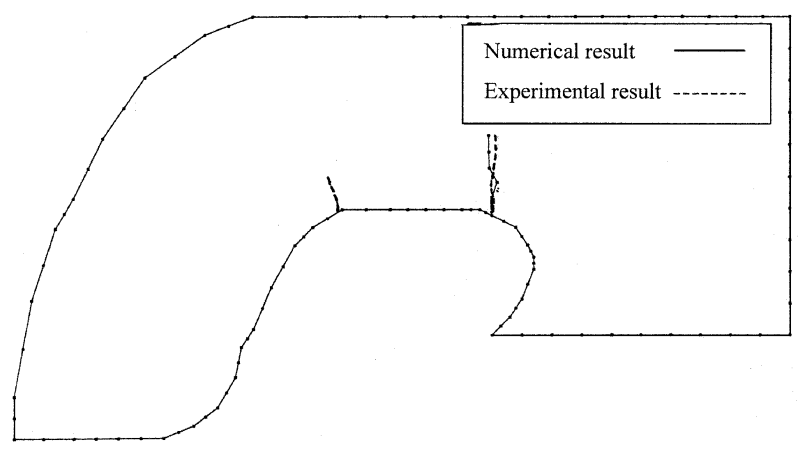

Fig. 16 NDT X-ray and numerical result in case 4

and the coefficient of thermal expansion is $6.645 \times$ $10^{-5} 1 /{ }^{\circ} \mathrm{C}$. Fig. 16 shows the predicted path of crack growth by using the dual BEM and the result matches well with the NDT observation (Chen and Leu, 1998), which is shown in Fig. 16.

\section{CONCLUSIONS}

The dual boundary element method has been used to solve crack problems with analytical solutions and has been applied to crack problems of a V-band structure and a solid rocket motor with a stress reliever. Results show that the DBEM provides high solution accuracy and greatly simplifies the modeling. DBEM involves modeling only on the boundary without introducing the artificial boundary which the multi-zone method needs. Only a single-domain approach can be achieved. Also, the path of the crack growth was predicted. The results have been compared with FEM solutions, analytical solutions, and experimental data, and were found to be in acceptable agreement.

\section{REFERENCES}

1. Banerjee, P.K., and Butterfield, R., 1981, 
Boundary Element Method in Engineering Science, McGraw-Hill, New York.

2. Bannantine, J.A., Comer, J.J., and Handrock, J. L., 1990, Fundamentals of metal fatigue analysis, Prentice Hall.

3. Broek, D., 1988, The Practical Use of Fracture Mechanics, Kluwer, London.

4. Buecker, H.F., 1973, "Field Singularities and Related Integral Representations," Mechanics of Fracture, Vol. 1, G. C. Sih, ed.

5. Chen, J.T., and Chen, K.H., 1998, “Dual Integral Formulation for Determining the Acoustic Modes of a Two-dimensional Cavity with a Degenerate Boundary," Engineering Analysis with Boundary Element, Vol. 21, pp. 105-116.

6. Chen, J.T., and Chen, K.H., 1998, "Dual Boundary Element Analysis for a Cavity Containing an Incomplete Partition," The Chinese Journal of Mechanics, Vol. 14, pp. 1-11 (in Chinese).

7. Chen, J.T., and Hong, H.K., 1992, Boundary Element Method, New World Press, 2nd Ed., Taipei, Taiwan (in Chinese).

8. Chen, J.T., and Hong, H.K., 1993, "On the Dual Integral Representation of Boundary Value Problem in Laplace Equation," Boundary Elements Abstracts, Vol. 4, pp. 114-116.

9. Chen, J.T., and Hong, H.K., 1999, "Review of Dual Boundary Element Methods with Emphasis on Hypersingular Integral and Divergent Series," Transactions of ASME, Applied Mechanics Reviews, Vol. 52, pp. 17-33.

10. Chen, J.T., Hong, H.K., and Chyuan, S.W., 1994, "Boundary Element Analysis and Design in Seepage Flow Problems with Sheetpiles," Finite Element Analysis and Design, Vol. 17, pp. 1-20.

11. Chen, J.T., and Leu, S.Y., 1998, "Finite Element Analysis, Design and Experiment on Solid Propellant Motors with a Stress Reliever," Finite Element Analysis and Design, Vol. 29, pp. 7586.

12. Chen, J.T., Lin, S.L., Chiou, C.Y., Chyuan, S.W., Hwang, J.Y., Harn, W.R., and Chin, W.T., 1996, Finite Element Analysis and Engineering Applications Using MSC/NASTRAN, Northern Gate Publications, Taipei, Taiwan (in Chinese).

13. Chen, J.T., and Wong, F.C., 1998, "Dual Formulation of Multiple Reciprocity Method for the Acoustic Mode of a Cavity with a Thin Partition," Journal of Sound and Vibration, Vol. 217, pp. 75-95.

14. Chyuan, S.W., and Liu, D.C., 1996, "Failure Analysis and Modeling of a V-band Type Joint Structure," Proceedings of the 4th R. O. C. Sym. on Frac. Sci., pp. 87-93 (in Chinese).

15. Erdogan, F., and Sih, G.C., 1972, "On the Crack Extension in Plates under Plane Loading and
Transverse Shear," Journal of Basic Engineering, Vol. 8, pp. 114-117.

16. Fedelinski, P., and Aliabadi, M.H., 1994, "The Dual Boundary Element Method: J-integral for Dynamic Stress Intensity Factors," International Journal of Fracture, Vol. 65, pp. 369-381.

17. Hadamard, J., 1952, "Lectures on Cauchy's Problem in Linear Partial Differential Equations," Dover Publications, New York.

18. Hartmann, F., 1981, "The Somigliana Identity on Piecewise Smooth Surfaces," Journal of Elasticity, Vol. 11, pp. 403-423.

19. Hartmann, F., 1982, "Elastic Potentials on Piecewise Smooth Surfaces," Journal of Elasticity, Vol. 12, pp. 31-50.

20. Hong, H.K., and Chen, J.T., 1988, "Derivation of Integral Equations in Elasticity," Journal of Engineering Mechanics, ASCE, Vol. 114, pp. 1028-1044.

21. Irwin, G.R., 1957, “Analysis of Stresses and Strains near the End of a Crack Traversing a Plate," Transactions of ASME, Journal of Applied Mechanics, Vol. 24, pp. 361-364.

22. Kayupov, M.A., Partheymuller, P., and Kuhn, G., 1999, "Dual BEM to Model Cracks in Strained Rock Samples", ZAMM, Vol. 79, pp. 507-508.

23. Leitao, V., Aliabadi, M.H., and Rooke, D.P., 1995, “The Dual Boundary Element Formulation for Elastoplastic Fracture Mechanics," International Journal for Numerical Method in Engineering, Vol. 38, pp. 315-333.

24. Lie, S.T., and Lan, S., 1998, "A Boundary Element Alalysis of Misaligned Load-carrying Cruciform Welded Joints," International Journal of Fatigue, Vol. 20, pp. 433-439.

25. Liu, D.C., and Chyuan, S.W., 1996, "Fatigue Life Prediction of a Ring Type Structure in the Vibrational Environment with Stress Corrosion Cracking Effect," Preceedings of the 4th R. O. C. Sym. on Frac. Sci., pp. 111-117 (in Chinese).

26. Mi, Y., and Aliabadi, M.H., 1992, "Dual Boundary Element Method for Three Dimensional Fracture Mechanics Analysis," Engineering Analysis with Boundary Element, Vol. 10, pp. 161-171.

27. Paris, P.C., 1962, "The Growth of Fatigue Cracks Due to Variations in Load," Ph.D. Thesis, Lehigh University.

28. Portela, A., Aliabadi, M.H., and Rooke, D.P., 1992, "The Dual Boundary Element Method: Effective Implementation for Crack Problems," International Journal for Numerical Method in Engineering, Vol. 33, pp. 1269-1287.

29. Portela, A., Aliabadi, M.H., and Rooke, D.P., 1993, "Dual bounary element incremental analysis of crack propagation," Computer and Structures, Vol. 46, pp. 237-247. 
30. Salgado, N.K., and Aliabadi, M.H., 1998, "The boundary element analysis of cracked stiffened sheets, reinforced by adhesively bounded patches," International Journal for Numerical Method in Engineering, Vol. 42, pp. 195-217.

31. Wang, C.S., Chu, S., and Chen, J.T., 1990, "Boundary Element Method for Predicting Store Airloads During its Carriage and Separation Procedures," In: Grilli, S., Brebbia, C.A. and Cheng, A.H.D. editors, Computational Engineering with Boundary Elements, Vol. 1: Fluid and
Potential Problems, pp. 305-317.

32. Williams, J.G., 1984, Fracture mechanics of polymers, John Wiley \& Sons, New York.

Discussions of this paper may appear in the discussion section of a future issue. All discussions should be submitted to the Editor-in-Chief.

Manuscript Received: Nov. 18,1999

Revision Received: Dec. 20, 1999 and Accepted: Jan. 18, 2000

\title{
飛彈結構疲勞行為之對偶邊界元素法分析
}

\author{
全湘偉 ${ }^{1} \quad$ 林建華 ${ }^{2} \quad$ 陳正宗 ${ }^{2} \quad$ 劉導淳 ${ }^{1}$ \\ 1 台灣龍潭中山科學研究院 \\ 2 台灣基隆海洋大學河海工程學系
}

\begin{abstract}
摘 要
本文使用洪及陳 (1988) 所發展的對偶邊界元素法分析飛彈結構的疲勞行 爲。此方法結合二個獨立的邊界積分方程式, 兩式可同時考慮裂縫邊界的兩 側, 有效地使用單一領域即可處理裂縫問題。包括應力強度因子的計算結果以 及裂縫成長路徑之預測, 將與有限元素法做比較, 其中有二個實際應用例分別 爲含裂縫之 $\mathrm{V}$ 型環以及固體火箭發動機, 經與實驗結果做比較, 可得到一致的 結果。

關鍵詞：邊界元素, 破壞容損, 疲勞裂縫成長, 破壞力學與應力強度因子。
\end{abstract}

